University of Pennsylvania Carey Law School

Penn Law: Legal Scholarship Repository

Faculty Scholarship at Penn Law

6-21-2018

\title{
Informed Consent and the Role of the Treating Physician
}

\author{
Eric Feldman \\ University of Pennsylvania Carey Law School \\ Holly Fernandez Lynch \\ Perelman School of Medicine, University of Pennsylvania \\ Steven Joffe \\ Perelman School of Medicine, University of Pennsylvania
}

Follow this and additional works at: https://scholarship.law.upenn.edu/faculty_scholarship

Part of the Bioethics and Medical Ethics Commons, Ethics and Political Philosophy Commons, Health Law and Policy Commons, Health Policy Commons, Law and Society Commons, Medical Jurisprudence Commons, Policy History, Theory, and Methods Commons, and the Public Law and Legal Theory

Commons

\section{Repository Citation}

Feldman, Eric; Lynch, Holly Fernandez; and Joffe, Steven, "Informed Consent and the Role of the Treating Physician" (2018). Faculty Scholarship at Penn Law. 2031.

https://scholarship.law.upenn.edu/faculty_scholarship/2031

This Article is brought to you for free and open access by Penn Law: Legal Scholarship Repository. It has been accepted for inclusion in Faculty Scholarship at Penn Law by an authorized administrator of Penn Law: Legal Scholarship Repository. For more information, please contact PennlawIR@law.upenn.edu. 


\section{H E A L T L AW, ETH I C , A N D H U A N R I G T S}

\section{Informed Consent and the Role of the Treating Physician}

Holly Fernandez Lynch, J.D., M.B.E., Steven Joffe, M.D., M.P.H., and Eric A. Feldman, J.D., Ph.D.

In the century since Justice Benjamin N. Cardozo famously declared that "[e]very human being of adult years and sound mind has a right to determine what shall be done with his own body," informed consent has become a central feature of American medical practice. In an increasingly team-based and technology-driven system, however, who is - or ought to be - responsible for obtaining a patient's consent? Must the treating physician personally provide all the necessary disclosures, or can the consent process, like other aspects of modern medicine, take advantage of specialization and division of labor? Analysis of Shinal v. Toms, a recent Pennsylvania Supreme Court case, demonstrates the dangers of a narrow, rigid approach to consent.

\section{LEGAL TROUBLE}

In 2008, Dr. Steven Toms performed a total resection of a recurrent craniopharyngioma on Ms. Megan Shinal. During the procedure, he perforated her carotid artery, which led to permanent severe neurologic injury. Ms. Shinal sued, claiming that Dr. Toms had failed to explain the risks of the surgery and that had she known that a lower-risk subtotal resection was an option, she would have pursued that alternative instead. ${ }^{2}$

Dr. Toms testified at trial that during an initial consultation, he had discussed with Ms. Shinal her goals and the risks and benefits of total versus subtotal resection, including the potential harm that ultimately occurred. Ms. Shinal decided to undergo surgery, but the question of whether to proceed with total versus subtotal resection was at that time unresolved. ${ }^{2}$

Ms. Shinal subsequently spoke with Dr. Toms's physician assistant about scarring, the craniotomy incision, potential radiation, and the date for surgery. Thereafter, she signed a consent form that gave Dr. Toms permission to perform "a resection of recurrent craniopharyngioma" and that identified the risks of the surgery as including "injury and death," among others. The form indicated that Ms. Shinal had discussed the risks and benefits of alternative treatments, that she had been given the opportunity to ask questions, and that she had been given sufficient information to make her decision. However, the form did not specifically address the differential risks of the two surgical options. ${ }^{2}$

The jury was instructed that when assessing whether Dr. Toms had satisfied his legal duty to obtain consent, it could consider information that had been communicated to Ms. Shinal "by any qualified person acting as [his] assistant . . . ." The jury returned a verdict in the doctor's favor, which was affirmed by the intermediate appellate court. However, in June 2017, a divided Pennsylvania Supreme Court reached a different conclusion. In a 4-to-3 decision, it held that a physician may not "fulfill through an intermediary the duty to provide sufficient information to obtain a patient's informed consent," such that the jury instruction at trial had been incorrect. ${ }^{2}$

In reaching that conclusion, the Shinal majority opinion pointed to Pennsylvania precedent holding that a hospital has no duty to obtain a patient's informed consent, because "only the physician who performs the operation on the patient" bears that duty. ${ }^{3}$ Although that previous case did not address whether the physician must personally execute the duty, the Shinal majority took it to mean that a physician cannot rely on a subordinate to make requisite consent disclosures. ${ }^{2}$ In particular, the majority expressed concern about the "primacy of the physician-patient relationship," arguing that "[w]ithout direct dialogue and a two-way exchange between physician and patient, the physician cannot be confi- 
dent that the patient comprehends the [necessary information]." ${ }^{2}$

The majority opinion also referred to the relevant statutory text in the Pennsylvania Medical Care Availability and Reduction of Error (MCARE) Act, which provides that "a physician owes a duty" to obtain a patient's informed consent before performing surgery, inserting a surgical device, administering an experimental product or using an approved product in an experimental manner, or administering anesthesia, radiation, chemotherapy, or a blood transfusion. ${ }^{4}$ On the basis of this explicit reference to the physician, the majority held that the plain language of the statute requires treating physicians to satisfy their informed-consent duty directly and that conversations between the patient and others are irrelevant to satisfaction of the physician's duty. With this holding, the court overruled earlier Pennsylvania cases holding that the validity of consent does not depend on the identity of the person making the disclosures. ${ }^{5,6}$

Elsewhere in the statute, the MCARE Act provides that "[c]onsent is informed if the patient has been given a description of" the relevant procedure and its risks and alternatives. ${ }^{4}$ The dissenting opinion in Shinal seized on that passive language to argue that the statute does not specify who must provide patients with the relevant information and that "physicians should not be needlessly charged with the responsibility of being involved personally with every conceivable aspect of their practices that may assist them in informing their patients' consent."

The majority and dissent both agreed that the treating physician bears the duty to obtain patient consent; the disagreement was about how this duty may be discharged. Since Shinal, Pennsylvania physicians are legally required to perform this duty on their own. Because the Pennsylvania Supreme Court is the highest court in the state, its interpretation of the law is not appealable. The case has been returned to the lower court for a new trial under the legal standard set forth by the majority's ruling.

IMPLICATIONS IN PENNSYLVANIA AND BEYOND

Shinal has already had a profound effect in Pennsylvania, where it represents a substantial departure from typical consent practice. More than half the physicians who responded to a recent survey conducted by the Pennsylvania Medical Society (PAMED) reported a change in the informed-consent process in their work setting; of that group, the vast majority expressed discontent with the effect of the new approach on patient flow and the way patients are served. ${ }^{8}$ Medical centers throughout the state have changed their consent policies, precluding nonphysicians from obtaining patient consent to the procedures specified in the MCARE Act and sometimes restricting the involvement of physician trainees. Some Pennsylvania institutions have also applied the Shinal holding to research, in light of the reference in the MCARE Act to experimental products and uses, despite the clear policy of the Food and Drug Administration (FDA) allowing investigators to involve other staff in the consent process. ${ }^{9,10}$ The PAMED has indicated its intention to pursue legislative advocacy in response to the decision, ${ }^{8}$ but there has been no legislative action to date.

Although the Shinal decision is not binding outside of Pennsylvania, cases bearing on critical ethical dimensions of consent have a history of influence beyond their own jurisdictions.,11 We believe that Shinal has similar potential, especially because other state laws also include language that could be interpreted as requiring that disclosure be made directly by the treating provider (Table 1). Attorneys familiar with Ms. Shinal's success in Pennsylvania are likely to advance similar arguments in other states, perhaps successfully.

Even if Shinal is not a harbinger of a national trend, the case invites a broader conversation and careful analysis of unresolved ethical questions regarding the "who" and "how" of informed consent; these questions have received substantially less attention than the matter of "what" must be disclosed and understood. Should the Pennsylvania legislature allow the Shinal holding to stand? Should other states adopt the approach delineated by Shinal? We think not. We believe there are many ways to ensure that patients have the information and support they need to make decisions that cohere with their preferences - the ultimate goal of informed consent - without mandating that treating physicians exercise their consent duty alone, absent assistance from other members of the care team. 
Table 1. Selected State Informed-Consent Laws.

\begin{tabular}{|c|c|c|}
\hline State & Statutory Language & Relevant Case Law \\
\hline Pennsylvania & $\begin{array}{l}\text { ". . a physician owes a duty to a patient to } \\
\text { obtain the informed consent of the patient } \\
\text { or the patient's authorized representative } \\
\text { prior to conducting [various procedures]." } \\
\text { "Consent is informed if the patient has been given } \\
\text { [the required information]. The physician shall } \\
\text { be entitled to present evidence of the descrip- } \\
\text { tion of that procedure and those risks and alter- } \\
\text { natives that a physician acting in accordance } \\
\text { with accepted medical standards of medical } \\
\text { practice would provide." }\end{array}$ & $\begin{array}{l}\text { Valles v. Albert Einstein Medical } \\
\text { Center: Hospitals do not owe } \\
\text { a duty of informed consent, } \\
\text { which is held only by the } \\
\text { treating physician. }{ }^{3} \\
\text { Shinal } v \text {. Toms: The duty to obtair } \\
\text { patient consent may be per- } \\
\text { formed only by the treating } \\
\text { physician. }{ }^{2}\end{array}$ \\
\hline New York & $\begin{array}{l}\text { "Lack of informed consent means the failure of } \\
\text { the person providing the professional treat- } \\
\text { ment or diagnosis to disclose to the patient } \\
\text { such alternatives thereto and the reasonably } \\
\text { foreseeable risks and benefits involved as a } \\
\text { reasonable medical, dental or podiatric prac- } \\
\text { titioner under similar circumstances would }\end{array}$ & $\begin{array}{l}\text { Hoffson v. Orentreich }{ }^{11} \text { : The stat- } \\
\text { ute does not expressly pre- } \\
\text { clude use of an agent to pro- } \\
\text { vide information to a patient } \\
\text { on behalf of the treating pro- } \\
\text { vider (relying on a pre-Shinal } \\
\text { Pennsylvania case }{ }^{5} \text { ). }\end{array}$ \\
\hline
\end{tabular}

ient to make a knowledgeable evaluation."

Oregon "In order to obtain the informed consent of a patient, a physician or physician assistant shall explain the following: (a) In general terms the procedure or treatment to be undertaken; (b) That there may be alternative procedures or methods of treatment, if any; and (c) That there are risks, if any, to the procedure or treatment." ${ }^{13}$

"After giving the [initial explanation], the physician or physician assistant shall ask the patient if the patient wants a more detailed explanation. If the patient requests further explanation, the physician or physician assistant shall disclose in substantial detail the procedure, the viable alternatives and the material risks unless to do so would be materially detrimental to the patient." ${ }^{13}$

Texas ". . . the physician or health care provider shall disclose to the patient or person authorized to consent for the patient the risks and hazards involved ...."14

"Health care provider" includes any person or institution licensed to provide health care in the state. ${ }^{14}$

Statutory requirements are satisfied if consent is given in writing, signed by the patient or authorized representative, and "the written consent specifically states the risks and hazards." ${ }^{14}$

Wisconsin "Any physician who treats a patient shall inform the patient about the availability of reasonable alternate medical modes of treatment and about the benefits and risks of these treatments." 16
Brooks v. Physicians Insurance Company of Wisconsin, Inc. ${ }^{17}$ : The obligation to obtain consent lies with the physician. Here, the physician discussed the relevant procedures with the patient. The law does not require the physician to directly obtain the patient's signature on the consent form.

Rubedorv. Kopp ${ }^{18}$ : At trial, permitting a jury instruction that the treating physician may "delegate to another physician the informed consent process," but must verify adequate disclosure.

\section{Analysis}

The statutory language clearly recognizes the physician's duty but is ambiguous as to whether the physician must directly disclose the relevant consent information. The Valles case did not specify how the physician's consent duty must be discharged. Both the Shinal majority and dissent interpretations of the statutory text are plausible.

The New York statutory language could be viewed as more stringent than the Pennsylvania statute, because it directly references who is to disclose the relevant consent information. However, in Hoffson, a New York court (not the highest court in the state) interpreted the law flexibly to allow disclosure by others.

The Oregon statute specifically references physician assistants, which could make it more permissive than the reference only to physicians in the Pennsylvania statute. However, it is unclear whether the intent is to allow physician assistants to perform consent tasks on behalf of physicians in general or only when the physician assistant is performing a medical service directly for a patient.

Intermediate appellate courts in Texas have interpreted this statute flexibly to date, and the language may be more permissive than that for Pennsylvania, given the specific mention of other health care providers and the emphasis on written consent materials. However, mention of other health care providers could be interpreted as relevant only when there is no physician involved (e.g., for dental or chiropractic care) or in reference to institutional consent obligations.

Like the New York statute, this statute explicitly refers to disclosures by the treating physician, which is more stringent than the Pennsylvania statute. Relevant case law (although not from the highest court in the state) has permitted some flexibility, noting that disclosure by the treating physician is adequate to satisfy the duty even if someone else obtains the patient's signature. At least one trial court has permitted disclosure by someone other than the treating physician. 
PROMOTING HIGH-QUALITY INFORMED CONSENT THROUGH TEAMWORK

Achieving high-quality informed consent is complex. ${ }^{19}$ It requires patients who have the capacity to make the relevant decisions and circumstances that facilitate voluntary choice. It also requires adequate disclosure of material information to patients, as well as their comprehension of that information and an ability to fit it into the larger context of their lives and goals. ${ }^{20}$ To achieve these ends, health professionals seeking consent must have sufficient expertise, judgment, and training to know what to disclose and how to respond to questions. ${ }^{19}$ Strong communication skills are critical, as is adequate time. ${ }^{19}$ In a Department of Veterans Affairs study of 575 patients scheduled for elective surgeries, $60 \%$ of consent conversations took 10 minutes or more, and shorter conversations were associated with a substantial decrement in patient comprehension. ${ }^{21}$ However, the National Ambulatory Medical Care Survey showed that, in 2015, patients spent 15 minutes or less with the physician at $43 \%$ of office visits and spent 16 to 30 minutes with the physician at $42 \%$ of visits, ${ }^{22}$ during which time a variety of activities had to be accomplished. Time is also relevant in the sense that leading consent discussions is a skill that must be practiced and perfected - it is not automatically bestowed on newly minted physicians. ${ }^{23}$

Consider that at present, "physicians and patients rarely achieve the theoretical ideal" ${ }^{19}$ when it comes to informed consent, "physician-led informed consent discussions are often ill-timed or ineffective," ${ }^{24}$ and in outpatient practice, few patient decisions are adequately informed. ${ }^{25}$ Perhaps with more time physicians would do better, but this could result in longer wait times, more difficulty securing appointments, and higher costs. ${ }^{7,8}$ From the patient's perspective, physicians' time may be better spent on those specialized tasks that only they have the skill to perform, while other members of the team participate in the consent process as they do in other clinical tasks for which they are appropriately trained and supervised. This is not to suggest that we place efficiency above the quality of consent in terms of importance or priority; instead, we maintain that both goals can be achieved simultaneously.

Other members of the care team - including physician assistants, nurses, and others - often possess the skills and characteristics needed to conduct or enhance a high-quality discussion of consent. ${ }^{26}$ Accordingly, we believe it is ethically acceptable, and ought to be legally permissible, to allow treating physicians to rely on these team members for help in performing their consent duties. For example, the treating physician could describe the patient's options at a high level and make a preliminary recommendation for an appropriate course of treatment. A qualified professional under the physician's supervision could then educate the patient further about the risks and benefits of relevant alternatives, with substantial attention to eliciting the patient's values and goals. Finally, the treating physician could rejoin this ongoing process to address any remaining questions and uncertainties, assisting the patient in confirming a final decision. ${ }^{20} \mathrm{We}$ suspect that the patient would probably emerge from this process more informed and would make a decision with more confidence than would have been possible after a short office visit with the treating physician. Indeed, although the Shinal majority expressed concern that allowing physicians to "delegate the provision of critical information to staff" could "undermine patient autonomy and bodily integrity by depriving the patient of the opportunity to engage in a dialogue with his or her chosen health care provider," ${ }^{2}$ the approach suggested here would offer the patient support in reaching the best decision.

MAINTAINING A NONDELEGABLE DUTY

Although we argue that the treating physician may ethically seek the assistance of others in performing the tasks involved in obtaining consent, delegating those tasks does not necessarily entail delegating ultimate responsibility. The tasks may be shared, but we maintain that the responsibility for achieving the goal of consent - an informed decision that accords with the patient's values and priorities - belongs to the treating physician alone.

To understand this distinction, consider two approaches to informed consent: "passing the buck" versus "the buck stops here." In the former, the treating physician is permitted to fully delegate the responsibility to obtain informed consent to others, so that if something goes wrong, the person to whom the duty was delegated is held responsible. In the latter, the treat- 
ing physician cannot delegate the responsibility - only the tasks. If the person to whom the tasks are delegated fails, the treating physician remains responsible. Which approach is preferable?

If the buck is passed in the sense that the consent duty itself is transferred from the treating physician to others, there is a risk that responsibility will be diffused, leading to confusion, error, and potentially conflicting information. ${ }^{27}$ Just as it is important to have a single party who is responsible for coordinating a patient's care when various competent specialists are involved, it seems important to have someone who is ultimately responsible for the informed consent process - someone who oversees the process and is held accountable for failures. Moreover, imposing liability on the treating physician should help ensure that patients' needs are satisfied and their rights to autonomy protected, because it provides incentives for both the establishment of good consent practices and appropriate oversight in individual cases. We argue that if others who have been tapped to take part in the consent process do a sufficient job, the treating physician's duty should be deemed satisfied, even if the treating physician merely assigned the relevant tasks. However, we maintain that if those with whom the treating physician shares the tasks involved in obtaining consent perform inadequately, the buck should stop with the treating physician. This is precisely the approach advocated by the Shinal dissent, which argued that "[i]f qualified staff is somehow negligent in aiding a physician in informing a patient's consent, then the physician remains liable . . ..."

There is one legal caveat: in most states (although not Pennsylvania), ${ }^{3}$ a physician's institution also may be liable for failures to obtain informed consent, in addition to or instead of the physician. But the important point here is that, in our view, the buck should never be passed down from the treating physician to supporting staff.

\section{RECOMMENDATIONS}

Despite the understandable impulse to avoid litigation, we believe it is a mistake to allow the consent process to be shaped by fear of liability, ${ }^{7}$ encouraging repetition of shared tasks just to be on the "safe side." This approach risks eliminat- ing the benefits to the patient and the gains in efficiency associated with relying on others. Instead, we propose that treating physicians should do two things. First, we suggest that they establish the right structures to support those with whom they plan to share the tasks involved in consent. Do the supporting actors have the training, expertise, tools, and time necessary to perform their portion of the consent process? Do they know what is expected of them? The treating physician may wish to audit the process periodically, but assuming all is in order, we argue the physician should feel confident that the duty to secure consent is being adequately discharged. Second, we suggest that the treating physician should, before performing the procedure in question, speak with the patient to confirm that consent discussions have indeed taken place with the appropriate people, that all questions have been answered, and that the patient is secure in the ultimate treatment decision. We are not proposing elimination of "direct dialogue" or "two-way exchange between the physician and patient," as the Shinal majority feared ${ }^{2}$; there is a middle ground between permitting abdication of physician engagement and refusing in a court of law to consider information provided to a patient by anyone other than the treating physician.

In our view, the insistence of the Shinal majority that the treating physician personally provide all consent-related disclosures is an anachronism in a team-based health care system. ${ }^{7}$ Allowing the tasks involved in consent to be shared with qualified professionals, while holding the treating physician responsible for achieving the goals of consent, should facilitate informed decision making by the patient while enabling physicians to preserve time for other clinical functions that only they can perform. We expect that such an approach will redound to the benefit of all patients.

\footnotetext{
Disclosure forms provided by the authors are available with the full text of this article at NEJM.org.

We thank Shanin Specter for critical comments on an earlier version of the manuscript from the perspective of an expert in personal injury law and Elizabeth Kelly for assistance with legal research.
}

From the Department of Medical Ethics and Health Policy, Perelman School of Medicine (H.F.L., S.J., E.A.F.), and the Leonard Davis Institute of Health Economics (H.F.L., S.J.), University of Pennsylvania, Children's Hospital of Philadelphia (S.J.), and University of Pennsylvania Law School (E.A.F.) - all in Philadelphia. 
1. Schloendorff v. Society of New York Hospital, 105 N.E. 92 (N.Y. 1914).

2. Shinal v. Toms, 162 A.3d 429 (Pa. 2017).

3. Valles v. Albert Einstein Medical Center, 805 A.2d 1232 (Pa. 2002).

4. Pennsylvania Medical Care Availability and Reduction of Error (MCARE) Act, 40 P.S. § 1303.504 (2002).

5. Bulman v. Myers, 467 A.2d 1353 (Pa. Super. Ct. 1983).

6. Foflygen v. Allegheny General Hospital, 723 A.2d 705 (Pa. Super. Ct. 1999).

7. Shinal v. Toms, 162 A.3d 429 (Pa. 2017) (Baer dissenting).

8. Pennsylvania Medical Society. Here's what Pennsylvania physicians are saying about informed consent: PAMED survey results (https://www.pamedsoc.org/detail/article/nformed-Consent -Survey).

9. Food and Drug Administration. Informed consent information sheet: guidance for IRBs, clinical investigators, and sponsors. Draft guidance. July 2014 (https://www.fda.gov/downloads/ RegulatoryInformation/Guidances/UCM405006.pdf).

10. Food and Drug Administration. Guidance for industry: E6(R2) Good Clinical Practice: integrated addendum to ICH E6(R1). March 2018 (https://www.fda.gov/downloads/Drugs/ Guidances/UCM464506.pdf).

11. Hoffson v. Orentreich, 144 Misc.2d 411. (Sup. Ct. N.Y. Cnty. 1989).

12. Limitation of medical, dental or podiatric malpractice action based on lack of informed consent, N.Y. Pub. Health L. § 2805-D (McKinney Supp. 1975).

13. Procedure to obtain informed consent of patient, O.R.S. § 677.097 (2013).

14. Duty of physician or health care provider, Tex. Civ. Practice \& Remedies Code $\$ 74.104$ (2003).

15. Vaughan v. Nielson, 274 S.W.3d 732 (Ct. App. San Antonio 2008).
16. Informed consent, Wisc. Stat. § 448.30. (2013).

17. Brooks v. Physicians Insurance Company of Wisconsin, Inc., No. 2010AP613 (Wisc. Cr. App., 3d Dist. 2011).

18. Rubedor v. Kopp, No. 2009AP3133 2011 (Wisc. Cr App., 4th Dist. 2011).

19. Hall DE, Prochazka AV, Fink AS. Informed consent for clinical treatment. CMAJ 2012;184:533-40.

20. Emanuel EJ, Emanuel LL. Four models of the physicianpatient relationship. JAMA 1992;267:2221-6.

21. Fink AS, Prochazka AV, Henderson WG, et al. Predictors of comprehension during surgical informed consent. J Am Coll Surg 2010;210:919-26.

22. Department of Health and Human Services, Centers for Disease Control and Prevention, National Center for Health Statistics. National Ambulatory Medical Care Survey: 2015 state and national summary tables. 2015 (https://www.cdc.gov/nchs/data/ ahcd/namcs_summary/2015_namcs_web_tables.pdf).

23. McClean KL, Card SE. Informed consent skills in internal medicine residency: how are residents taught, and what do they learn? Acad Med 2004;79:128-33.

24. Schenker Y, Meisel A. Informed consent in clinical care: practical considerations in the effort to achieve ethical goals. JAMA 2011;305:1130-1.

25. Braddock CH III, Edwards KA, Hasenberg NM, Laidley TL, Levinson W. Informed decision making in outpatient practice: time to get back to basics. JAMA 1999;282:2313-20.

26. Aaronson NK, Visser-Pol E, Leenhouts GH, et al. Telephonebased nursing intervention improves the effectiveness of the informed consent process in cancer clinical trials. J Clin Oncol 1996;14:984-96.

27. Koch VG. Delegating informed consent. Hastings Cent Rep 2017;47(6):5-6.

DOI: 10.1056/NEJMhle1800071

Copyright $(\odot 2018$ Massachusetts Medical Society. 